\title{
Thoughts on Scientific and Technological Innovation of Agricultural University Students
}

\author{
Wang Junzheng \\ Jilin Agricultural University \\ Changchun, China \\ E-mail: 595845966@qq.com \\ Hu Guixue* \\ Jilin Agricultural University \\ Changchun, China \\ E-mail: 58549097@qq.com
}

\author{
Liu Haijun \\ Jiujiang University \\ Jiujiang, China \\ E-mail:392507102@qq.com
}

\begin{abstract}
Anation without innovation ability is hard to stand in the forest of the world's advanced nations. As a developing agricultural country, the reform of the agricultural technology is essential, and agricultural colleges and universities of college students is the future society of agricultural science and technology with the main person and creator of, how to explore the students in agricultural colleges and scientific and technological innovation, and cultivating innovative talents has become the problem of solving the deepening educational reform and developing the activities of scientific and technological innovation and other aspects to explore, to explore the specific ideas on agricultural college students scientific and technological innovation.
\end{abstract}

Keywords- Agricultural Colleges; College Students; Scientific and Technological Innovation; Analysis; Countermeasures

The party's 18 report: The full implementation of quality education, deepen the comprehensive reform of the field of education, efforts to improve the quality of education, cultivating students' innovative spirit. China is a large agricultural country in building a moderately prosperous society in the process, solve the "three rural" issue is the key, and agricultural college students are the future of the main application of social science and technology, agriculture and creators. This scientific and technological innovation of college students in agricultural universities put forward new demands. Therefore, how to explore new ideas and agricultural college students of science and technology innovation becomes the key problems to be solved.

I. THE ANALYSIS OF THE MAIN PROBLEMS AND REASONS AGRICULTURAL COLLEGE STUDENTS WORK IN SCIENCE AND TECHNOLOGY INNOVATION.

\section{A. The Traditional Teaching Model Hampers the Development of Innovative Thinking of Students.}

Under examination-oriented education system, dimension scores on the measure leads to a single student classroom teaching, with the development of society, the community has become increasingly popular with the innovative quality of the people. Currently, most colleges and universities use the evaluation system is still based on test scores based, innovative education development is still not perfect, teaching methods used mostly Church I teaching, too much emphasis on exam scores. For the students hands-on ability to improve the practice would not achieve a positive effect. Innovative Quality Higher Education Reform is urgent.

\section{B. Not Enough Emphasis on Innovative Education.}

Party eighteen full report, "innovation" has been mentioned 55 times, showing innovation for the development of the nation, the great rejuvenation of the Chinese nation has an extremely important role. However, in today's college educational system, to carry out innovative education is still relatively backward. Colleges and universities are important channels for social output of talent. "Qian of the question" is reflection, if universities this "source" have ignored the importance of innovation and education, then the creative community as a whole will be left behind.

\section{Backward Educational Content, Training System is Not Reasonable.}

Currently, the courses and educational content is relatively no longer able to keep up the pace. Educational content is the main line of teaching, there is a theory and practice of disconnection phenomenon, rarely times, keep up with technological frontier, and it cannot be the main line train students specializing in innovation. Training System is a program of school teaching, the current education system is not perfect innovation, and innovation cannot achieve good educational purpose, but needs to promote the teaching reform, promote the education sector join forces to establish a scientific and effective training mechanism.

\section{Teachers' Comprehensive Quality, Innovation Awareness Needs to be Improved.}

Teachers who preacher Tuition FAQ give the student a glass of water when he was going to have a bucket of water, many teachers leave the school door, and entered the school door, he began to learn the theory of teaching, 
lacking experience and sense of innovation, unable to educate students with a sense of innovation. This requires instructors, to practice and actively participate in research and innovation, enriching themselves, the concept of lifelong learning, and constantly improve their sense of innovation.

\section{E. Innovation Education did Not form Disciplines Together.}

Knowledge innovation, often the need to involve multiple disciplines, is difficult to have a single discipline interdisciplinary major breakthrough, to be carried out asymmetric breakthrough innovation without borders, to play professional disciplines together, which colleges and universities should actively encouraging interdisciplinary professional comprehensive research, and constantly improve the overall quality of talent.

\section{THE EXISTENCE OF ISSUES RELATED TO SCIENCE AND TECHNOLOGY INNOVATION OF AGRICULTURAL UNIVERSITY STUDENTS WORKING COUNTERMEASURES.}

\section{A. Deepen the Reform of Education, Training Creativity for College Students}

1) Teaching Students to be Adapted to the Requirements of Agricultural Innovation Quality.

To cultivate students' innovative spirit and practical ability to focus, to comprehensively strengthen students' innovative quality education is the focus of the current education reform. Cultivation of agricultural university students' innovative spirit and practical ability of the main front is agricultural production, scientific research and teaching, let the classroom full of vitality, strengthen the teaching and learning interactive, enable students to become the main learning and development, and to change the teaching mode, the single inheritance model, keeping type, duck-based teaching model into a pioneering thinking, development-oriented research, practice a variety of innovative teaching mode, teaching should be extended to agricultural production and research practice, the theory is applied practice to improve in practice the theory and practice of further guidance to enable students to participate in the entire process, learning and research practice in the production process, and strive to improve the quality of teaching. [1]

2) The Reform of Basic Education to Improve Agricultural Technological Innovation System

Construction of agricultural science and technology innovation system, the implementation of science and technology innovation education, cultivate innovative talents, is an important direction of China's basic education reform. The Cultivation of Agricultural Creative Talents need to reform the education system and educational content should run through the whole educational activities. [2] Forming a culture of innovation talents of agricultural environment and atmosphere. Strengthen the teaching infrastructure, teaching management, campus culture, practice teaching, as well as quality assurance and student assessment system. Including the construction of basic education platform, professional education platform, Innovative Training System Graduate Education Quality Assurance System, agricultural colleges and universities to promote the internationalization of education, promote international exchanges, improve the technological innovation system.

\section{3) Teaching Reform Should be Conducive to} Improving Students' Originality

Teaching to a high starting point, thick foundation, strict requirements, heavy practice, innovation, integration of teaching resources, take colleges, enterprises, schools and other models to jointly employ internal and external experts and professors considerable agricultural work experience to undergraduate lectures, resource advantage, direct starting point for business and local needs to teach students. And in-depth reform of professional selection mode, the first two years taking general education, strengthen basic education, before the end of sophomore year, according to the interests and knowledge structure, choose their favorite professional, help students learning initiative and creativity, to improve students' original force, more conducive to the cultivation of innovative thinking. Unassuming personality of students in the teaching process, take specialty education, encourage creative thinking, to enable students to acquire both comprehensive development and personality development, both to achieve education for all, and be individualized. The disagreement is not all negative in the teaching process, to look at the problem dialectical development of student's personality, ability to inspire students' originality, people-oriented, to stimulate student learning initiative.

4) Continue to Deepen the Reform of the Credit System to Encourage Students to Innovate

In credit management model based on the establishment flexible educational system, students can clear 3-6 years to complete their studies, allowing students to complete the learning stages, allowing students staged elective courses require students to complete as long as the appropriate discipline within the prescribed time limit credits Grade Point Average, you can graduate, adhere to the student, the student will have the conditions for free learning time cultivating innovative consciousness and innovative spirit, and the establishment of student innovation and Grade Point linked to student evaluation system. Allow students to research, innovation and expertise Innovation Competition achievements to replace Grade Point related courses to encourage students to actively participate in research, innovation and competition-related skills, in order to improve students' ability to innovate.

\section{B. Strengthen Scientific Management, Promote Innovation Guide}

1) Subject to strengthening the integration of scientific research institutions to promote the establishment of borderless innovation

Strengthening and integration of cross-disciplinary, scientific understanding of the relationship between teaching and research, relying on comprehensive scientific research platform, the establishment of research institutions, the implementation of diversified evaluation system, to break the disciplinary boundaries, integrating teaching resources, exploration asymmetric breakthrough, promote borderless innovation, clear development ideas, accelerate system and mechanism innovation, encourage scientific research project carried out jointly by various disciplines, etc., and to encourage students to participate in 
the relevant professional related topics, and in participation in learning, research and scientific practice, to strengthen the integration of the various disciplines of knowledge, expand their horizons and knowledge, science and technology for agricultural development.

2) the Establishment of an Innovative High-Quality Scientific and Technological Counseling Teachers to Guide Students to Innovate

Agricultural colleges must improve scientific and technological innovation quality to develop a practical experience with agricultural production, good at absorbing the latest teaching theory and research and to be able to utilize its production activities, play originality, and strive to cultivate teaching and Production dual-qualified tutors practice of combining to form a unique technology agricultural colleges counseling teachers, lay a solid foundation for the students' creative quality. The establishment of a team of old, young agricultural experts to guide students 'innovative team, formed pass, to help with team building, integration of teaching resources, talent advantage, and guide students' innovative activities.

3) Relying on Scientific and Technological Organizations, Strengthen Innovation Guide

Encourage students to students, science and technology associations and other organizations based on the establishment of professional associations relying on science and technology category, advantage of resources to carry out scientific and technological activities, and the establishment of the tech community steering group of experts, to guide students in health science and technology innovation, steadily, in give guidance in the work, provided the material guarantee, in order to strengthen the expertise to carry out the theme of science and technology services and innovation activities, open ideas, expand their horizons, and comprehensively improve the quality of students. Courage, hard thinking on the level of professional learning, seeking depth and strengthen academic building [3].

\section{4) Strengthening Practice Teaching Base} Construction Encourage Innovation in Practice

Through the demonstration area, teaching experimental field construction, practice entrepreneurial base construction and relying on the professional advantages carry out the "three rural" and other social practices. Ways to expand the practice to inspire students to continue to explore knowledge, the courage to create the desire to guide students in-depth first line of agricultural production practices were to go, the actual production of a wide range of contacts, find and solve practical problems in production, to combine research and practice, the paper write on the earth.

\section{Innovative Activities, Foster Innovation}

1) To Carry out Academic Exchanges and Create an Atmosphere of Science and Technology

Invite domestic and foreign agriculture known experts and scholars to give lectures to carry out activities, academic exchanges, and create an atmosphere of innovation, expand their horizons, to stimulate enthusiasm for innovation, enhance research. And learn through the dispatch of students abroad, sending teachers abroad for exchange, learn advanced technology and experience in the field of agricultural research, and in the case of the time is ripe to carry out cooperative education has collaborative research efforts with international practice, catch up with the world's advanced level of agricultural science and technology, efforts to create technological innovation atmosphere.

2) To Carry out Scientific and Technological Innovation to Enhance Education Guide

Campus cultural activities Extracurricular Scientific Activities for the body, is an innovative type of culture, it is bound to create innovative education students play an important role in guiding. [4] Through the "Challenge Cup" contest of scientific papers, "business plan" contest, "professional skills Innovation" contest and small inventions, small production competitions and other activities to encourage students to actively participate in scientific and technological activities, to enhance the practical ability and creative skills, and constantly sum up theoretical upgrade, published scientific papers, and then to guide agricultural production practices, forming a virtuous circle, promote innovation and development. In addition, a single assessment model to reform, to increase the practice of assessment and innovation assessment content, the only score on the break, and guide students to actively participate in science and technological innovation, and strive to cultivate innovative talents.

3) To Encourage Students to Participate in the Teacher's Research, Innovation and Practical Skills Upgrade

Students to participate in scientific research among teachers, under the guidance of their teachers, the students understand the project from the start basis, access to learning related knowledge, and carry out experimental work related to experience and hands-on practical skills to enhance innovation, thus improving the scientific and technological innovation enthusiasm and ability. At the same time, create conditions to guide students to the research project, to find research fun and inspire students to conduct scientific research initiative. To graduation, essay competitions as the starting point, and guide students to actively participate in research projects among research to feel the atmosphere of scientific research, learning methods of scientific experiments, increase the accumulation of knowledge, and identify problems, timely advice to the teacher, in the experiment, local solutions, and enhance the ability, which is agricultural university students foster innovation to enhance research level of a shortcut.

In short, agricultural innovative talents are not an overnight thing, to adapt to the world of agricultural science and technology development, hold high the banner of innovation, adhere to science and technology are primary productive forces, adhere to the papers written in the earth, and continuously explore, proactive talent to accelerate innovation in agricultural universities Training.

FUND PROJECT:The Department of Jilin Province Education Science "1025" planning research project "ordinary higher agricultural colleges and universities students innovative talents cultivation research model", one of the results, (serial number: GH150216) 


\section{REFERENCES}

[1] Zhou Yezhong. Theory of innovative talents cultivation and higher education reform [J]. Journal of Wuhan University,2002, (3), pp. 369-371,

[2] Cai Wei. The problems existing in the college students' science and technology innovation activity and countermeasures [J]. Journal of cCongqing Institute of Technology: social science edition, 2007, (6) , pp. 165-166.

[3] Shun-jie Han. College students' scientific and technological innovation practice base operation mechanism research [J]. Journal of Changchun University of Technology, higher education research, 2008, (2) , pp. 73-74.

[4] Luo gf. Scientific and technological innovation activities as the platform to promote university students' scientific literacy $[\mathrm{J}]$. Journal of three gorges university, humanities and social science edition, 2007 , pp. 190-191.
[5] Chen Xijian. Strengthen the realistic choice of university innovation education in the new period $[\mathrm{J}]$. Journal of heilongjiang education (higher education research and evaluation), 2006, (Z2), pp. 80-82.

[6] XiaoChuan. Through the Chinese and foreign exploring the road of university innovation education, evaluation of the university innovation education in the international field of vision "[J]. Journal of higher education research, 2006, (02) , pp. 105-107.

[7] Hui-qin li, Guo Xiaojing. The development of innovation education abroad and the enlightenment to our country $[\mathrm{J}]$. Chinese geological education, 2005, (3) , pp. 33-35.

[8] Xie Bingzhi. Actively promote research-based teaching to improve college students' innovation ability [J]. Journal of Liaoning education research, 2005, (6) , pp. 55-57.

[9] Xiu-mei cui, wei-guo han. About the thinking of college innovation education in the new period [J]. Journal of gansu aspect of science and technology, 2004, (5), pp.150-151. 